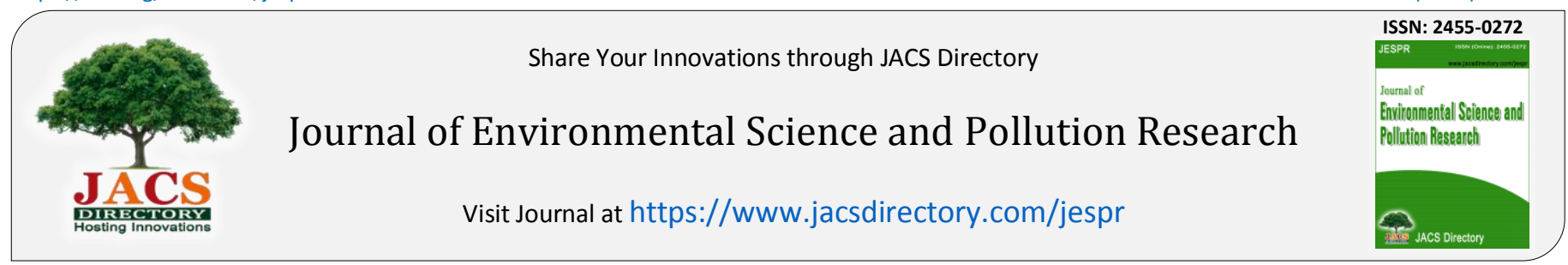

\title{
Association of Air Pollution Levels to Atmospheric Weather Regimes over Europe
}

\author{
Muntasir A. Ibrahim ${ }^{1, *}$, Gabriele Curci ${ }^{2}$, Farouk I. Habbani ${ }^{1}$, Fred Kucharski ${ }^{3}$, Paolo Tuccella ${ }^{2}$, Susanna Strada ${ }^{3}$ \\ ${ }^{1}$ Department of Physics, Faculty of Science, University of Khartoum, Khartoum - 11111, Sudan. \\ ${ }^{2}$ CETEMPS, Physical and Chemical Sciences, University of L'Aquila, L'Aquila - 67100, Italy. \\ ${ }^{3}$ Earth System Physics Section, The International Center for Theoretical Physics, Trieste - 34100, Italy.
}

\section{ARTICLEDETAILS}

Article history:

Received 27 December 2020

Accepted 08 February 2021

Available online 25 February 2021

\section{Keywords:}

Berlin Pollution Levels

Weather Regime Types

COST733 Project

Cluster Methods

\begin{abstract}
A B S T R A C T
The ability to link air pollution to weather regimes may help municipalities to activate in advance plans to protect citizens from severe episodes of air pollution. The aim of this work was to associate the atmospheric circulation patterns and air pollution over Berlin using observational data from three air quality monitoring stations (Urban, Suburban and Traffic stations) during the period January 1990 to December 2002, with weather type's classifications issued in the frame of the European Cooperation in Science and Technology project (COST733). Results obtained in this work shows similar higher ozone $\left(\mathrm{O}_{3}\right)$ concentrations and weather regime type during the summer season for both the three stations and the two cluster methods used viz. Self-Organizing Maps (SOM) and cluster analysis of principal components (CAP). The highest concentration level of ozone was observed in the suburban station. High pollution that occurred from the particulate matter $\left(\mathrm{PM}_{10}\right)$ was observed in the urban station during the winter season. The highest nitrogen dioxide $\left(\mathrm{NO}_{2}\right)$ value was observed in the traffic station during the spring season. However, the traffic station is probably not a very good indicator of the sensitivity of air quality in meteorology, because it is too much affected by local sources.
\end{abstract}

\section{Introduction}

Human and plant health in general and living conditions depend deeply on air quality conditions, which have an impact on the overall environment [1], which can be divided into two parts. The first part is the direct effect through the absorption and dispersion of sunlight and infrared radiation. The second part is the indirect effect due to the change in the characteristics of the process of intensifying the clouds. Air pollutants are emitted from a range of natural and human sources including the burning of fossil fuels used in electricity generation, transportation, industry, and solvent use such as in the chemical, mining, agriculture, and waste treatment industries (Fig. 1). Natural sources, such as volcanic eruptions, dust from wind, sea salt spray, and volatile organic compounds (VOC) emissions from plants [2]. Reducing these emissions is therefore important to improve air quality.

At the global level, air quality standards (AQS) were identified for air pollutants, such as nitrogen dioxide $\left(\mathrm{NO}_{2}\right)$, particulate matter $\left(\mathrm{PM}_{10}\right)$ and ozone $\left(\mathrm{O}_{3}\right)$. Several studies have reported the impact of climate patterns on the incidence of particulate and ozone pollution [3-7]. Similar studies for Northwest Europe were conducted by Buchholz [8], which showed that mixed-weather weather systems are associated with better air quality than other weather systems such as anti-hurricanes, Portugal by Russo [9].

The weather regime is defined as a continuous and/or recurring pattern in the atmosphere, which is associated with specific climate conditions on a regional scale. Circulation regimes represent an important dynamical feature of many non-linear models of the atmospheric circulation. It has been observed that weather patterns have a tendency to repeat themselves from time to time [10]. In recent years, several studies have focused on the classification of weather systems associated with air pollution and the impact of North Atlantic oscillations (NAO) on air quality. [11]. Christoudias et al. found that a strong anti-correlation between the NAO phase and the concentrations of pollutant gases in Western and Central Europe. It has been found that climate change towards NAO higher or lower has the potential to significantly influence urban air pollution in northwestern Europe, and thus the possibility of achieving air quality standards, even if emissions remain constant [12-14]. Several previous studies have been examined the impact of atmospheric circulation

patterns on the concentration of air pollution in different countries, such as in Turkey [15,16], Australia [17], United State [18], China [19], Taiwan [20], Southern Poland [21], Northeast Portugal [22], UK [23], Iberia [24], and Malaysia [25-27]. In general, weather systems with higher daily rainfall rates lead to better air quality than dried air masses due to the low $\mathrm{PM}_{10}$ contribution to the air quality index [28-31]. Zhong et al. [32] reported that the interaction between pollutant emissions and elementary meteorological conditions affects the fluctuation of $\mathrm{PM}_{2.5}$ concentrations in Beijing. Barros et al. [33] and Carvallo et al. [34] have suggested that air quality systems are generally similar in the northern and southern regions of Portugal considered except for spring and autumn $\mathrm{PM}_{10}$.

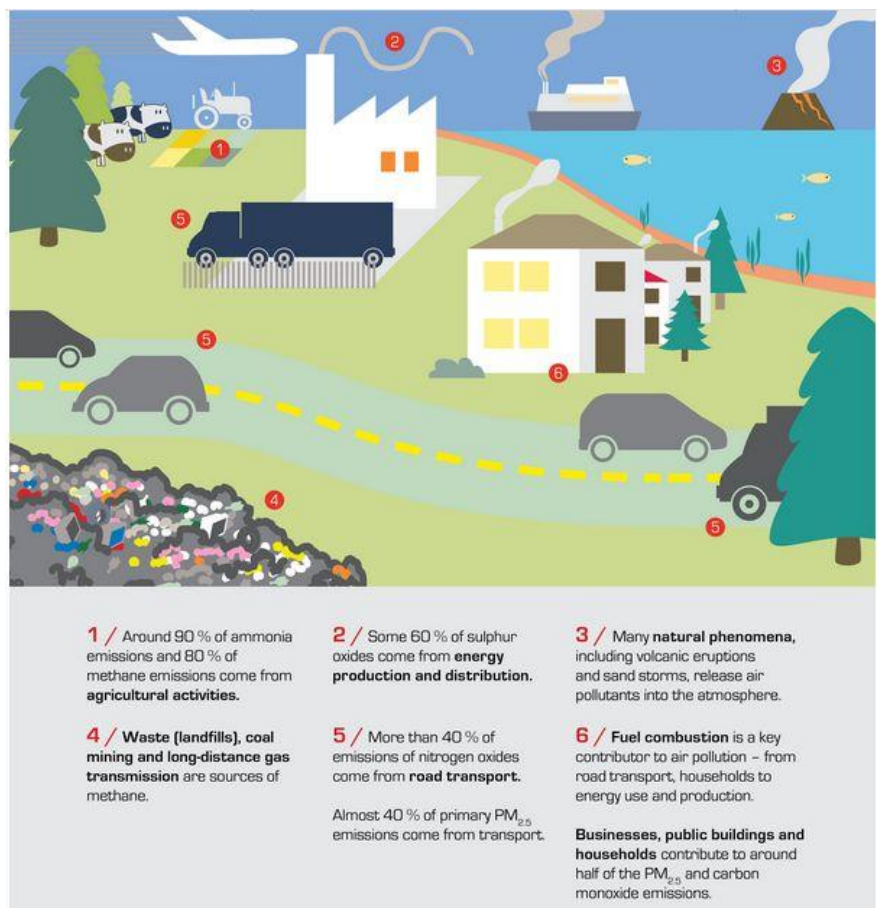

Fig. 1 The main sources of air pollution 
In this work, through the analysis of observed air pollution levels as a function of weather types, we attempt to find the answer to, What are the typical weather types resulting in high pollution levels in Europe?; What are the differences between ozone, nitrogen dioxide, and particulate matter?; How different are results when using different classification types?; What is a suitable number of weather types in the classification?; Are there differences among urban, suburban and traffic stations?.

\section{Experimental Methods}

\subsection{Data Collection, Sources and Standard}

The air pollutant data has been collected from three air pollution monitoring stations in Berlin during the period January 1990 - December 2002 for the species $\mathrm{O}_{3}$ (hourly), $\mathrm{NO}_{2}$ (hourly) and $\mathrm{PM}_{10}$ (daily). These stations are a traffic station, which symbolized by (DEBE014), an urban station (DEBE034) and a sub-urban station (DEBE051). The weather regime maps are produced manually using COST 733 scripts, dataset and software [35]. The European standards and the World Health Organization (WHO) guidelines are summarized in Table 1 . The given data apply over different periods of time because the observed health impacts associated with the various pollutants occur over different exposure times.

\section{$2.2 \operatorname{COST} 733$ - Action}

It started in the year 2005 within the Earth System Science and Environmental Management (ESSEM), and it is freely available to use [36]. The main objective of COST 733 (Fig. 2) is to achieve a general numerical method for assessing, comparing and classifying typical weather regimes in Europe [37]. The objective of COST 733 is to achieve a general numerical method for assessing, comparing and classifying typical weather regimes in Europe.

Table 1 The EU standards and the WHO guidelines.

\begin{tabular}{|c|c|c|c|c|}
\hline Pollutant & $\begin{array}{l}\text { Averaging } \\
\text { period }\end{array}$ & $\begin{array}{l}\text { Nature } \\
\text { concentration } \\
\text { level }\end{array}$ & Comments & $\begin{array}{l}\text { WHO } \\
\text { concentration } \\
\text { level }\end{array}$ \\
\hline$P M_{10}$ & One day & $\begin{array}{l}\text { Limit value is } 50 \\
\mu \mathrm{gm}^{-3}\end{array}$ & $\begin{array}{l}\text { Not to be exceeded } \\
\text { on more than } 35 \\
\text { days per year. }\end{array}$ & $50 \mu \mathrm{gm}^{-3}$ \\
\hline$O_{3}$ & $\begin{array}{l}8 \text { - hour } \\
\text { mean }\end{array}$ & $\begin{array}{l}\text { Target value is } \\
120 \mu \mathrm{gm}^{-3}\end{array}$ & $\begin{array}{l}\text { Not to be exceeded } \\
\text { on more than } 35 \\
\text { days per year, } \\
\text { averaged over three } \\
\text { years. }\end{array}$ & $100 \mu \mathrm{gm}^{-3}$ \\
\hline $\mathrm{NO}_{2}$ & One hour & $\begin{array}{l}\text { Limit value is } \\
200 \mu \mathrm{gm}^{-3}\end{array}$ & $\begin{array}{l}\text { Not to be exceeded } \\
\text { on more than } 18 \\
\text { times a calendar } \\
\text { year. }\end{array}$ & $200 \mu \mathrm{gm}^{-3}$ \\
\hline
\end{tabular}

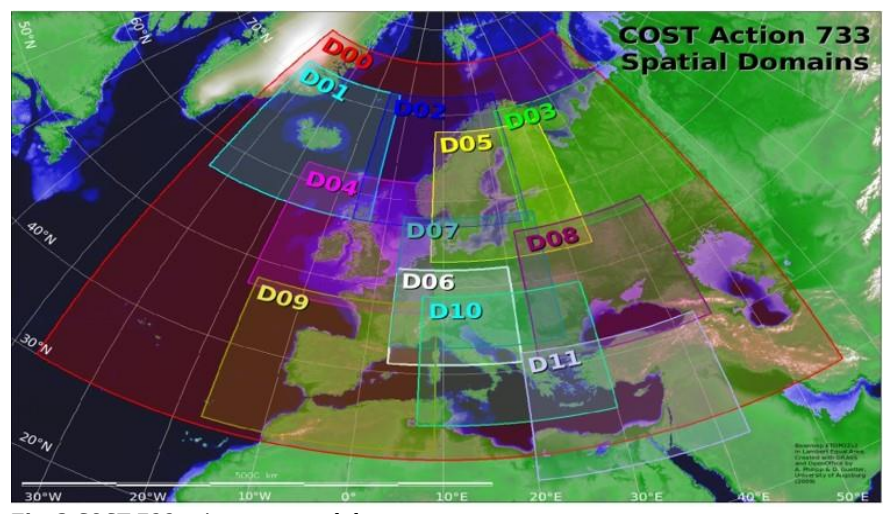

Fig. 2 COST 733 - Action spatial domains

\subsection{Weather Types Classification Methods}

Classification have a long history in meteorology and climatology. In the past, they were used mainly for weather forecasting. Recently, the usage of classifications has increased due to the advances in computational infrastructures and technology. Their application plays a vital role in the field of statistical climatology. The main objective of classifications is to translate multi-variate information given on the metrical scale in an input dataset. Clustering is defined as the process of dividing a given data into groups in such a way that patterns grouped together are more similar/closer than patterns in other groups. Cluster methods vary https://doi.org/10.30799/jespr.210.21070101 according to data pre-processing. In this work, for the analysis, we used the optimization algorithm methods. These methods including KMN (KMeans), PCA (Principal Component Analysis), CAP method, CKM (CK Means), PXK (PCA XtrKm), SAN (Sandra) and SOM method, which well described in many previous studies such as $[18,36]$. The purpose of the optimization method is to make an arrangement for a set of objects, such as the daily pressure maps, within clusters in such a way that a certain function is optimized. Among those mentioned methods the SOM method was used to analyze our results, and then compared the results obtained by the CAP method.

\subsection{SOM and CAP Cluster Methods}

The SOM method is a type of artificial neural network developed by Teuvo Kohonen, Academy of Finland [38]. Amongst cluster techniques, SOM is unique in that it generates two-dimensional grid with similar patterns nearby and dissimilar patterns widely separated. It describes a way to arrange types defined by their features in a structure where similar types are adjacent to each other. The aim of SOM is to reduce a large amount of data into a small number of representative patterns that capture a large fraction of the variability with spatial patterns that be similar to the observed data. Where the CAP method is a combination of PCA and KMN methods. CAP method is a two-stage procedure that contains the PCA method, which is responsible to derive the dominant patterns of variability, and KMN method that classify time series of the principal components.

\subsection{Linking between Weather Regime and Air Quality}

First, box plots were built, and then from these plots weather regimes (WR) were defined that favor a certain type of pollution (e.g. WR1 favors ozone pollution because ozone concentrations are the highest under weather conditions associated with WR 1). Afterward, weather maps produced with cluster methods and analyzed to check results and see if weather conditions associated with the selected WR could sustain polluted conditions. Fig. 3 describes how weather regime and air quality are linked together.

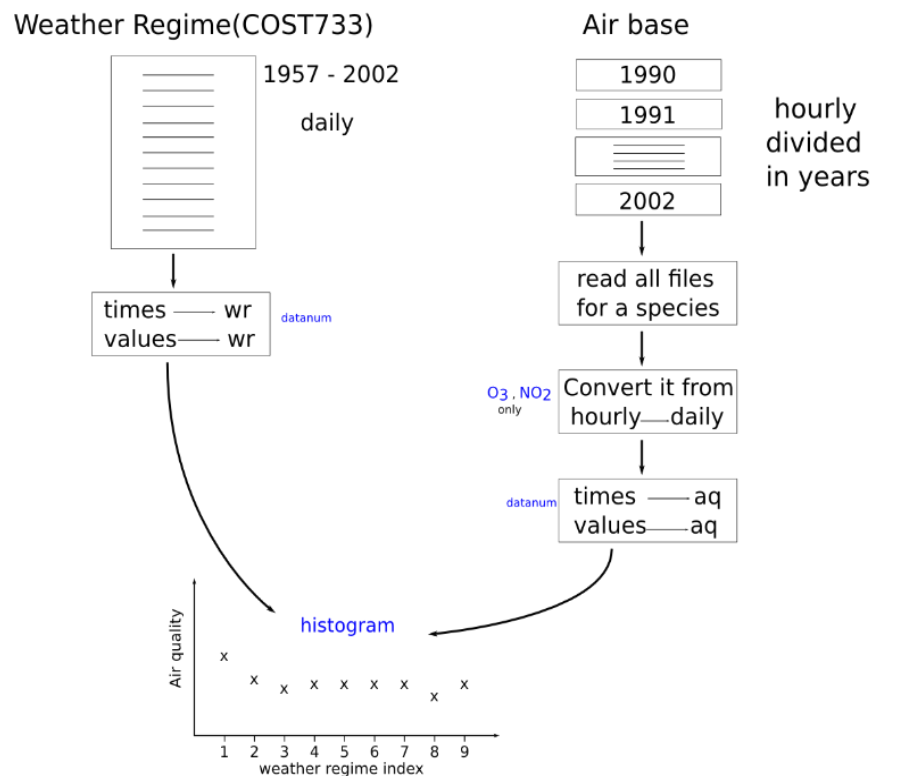

Fig. 3 Link between weather regime and air quality

\section{Results and Discussion}

\subsection{Photochemical Ozone Smog $\mathrm{O}_{3}$}

Ozone $\left(\mathrm{O}_{3}\right)$ is a colorless and toxic gas. It is produced in the presence of intensive solar radiation through a photochemical process from precursor substances such as nitrogen oxides and volatile organic compounds. Surface ozone is harmful to humans, plants and the environment. High daily concentrations risk can reduce pulmonary function and result in lung diseases. The box plots (Fig. 4) show the highest concentrations of ozone in the suburban station, and weather regime mean sea level pressure maps (MSLP) at the annual and summer scales for both SOM and CAP methods.

SOM: The highest median is $94 \mu \mathrm{gm}^{-3}$ associated with weather type 1 . The highest max value is $269{\mu \mathrm{gm}^{-3}}^{-}$associated with weather type 1 . CAP: The highest median is $94 \mu^{-3}$ associated with weather type 1 . The highest max value is $269 \mathrm{\mu gm}^{-3}$ associated with weather type 1. 

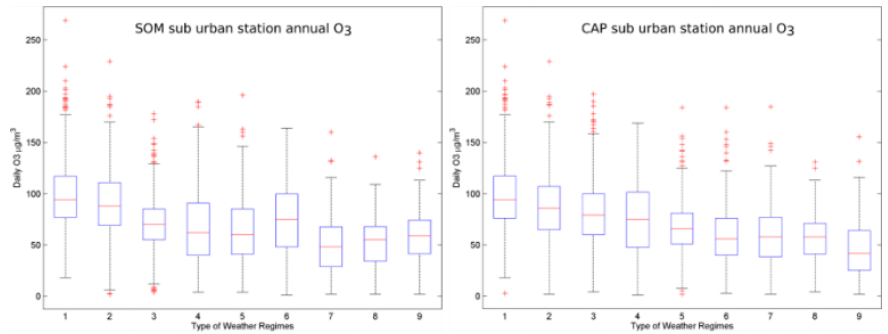

Fig. 4 Daily ozone concentrations and weather regime type in the annual scale for SOM and CAP methods

The box plots in Fig. 5 show the highest concentration during summer for both methods. Details obtained from the boxplots are: SOM: The highest median is $120 \mu^{-3}$ associated with weather type 1 . The highest max value is $269 \mu^{-3} \mathrm{gm}^{-3}$ associated with weather type 1 . CAP: The highest median is $109 \mu^{-3} \mathrm{gm}^{-3}$ associated with weather type 6 . The highest max value is $269 \mu^{-3}$ associated with weather type 1 .
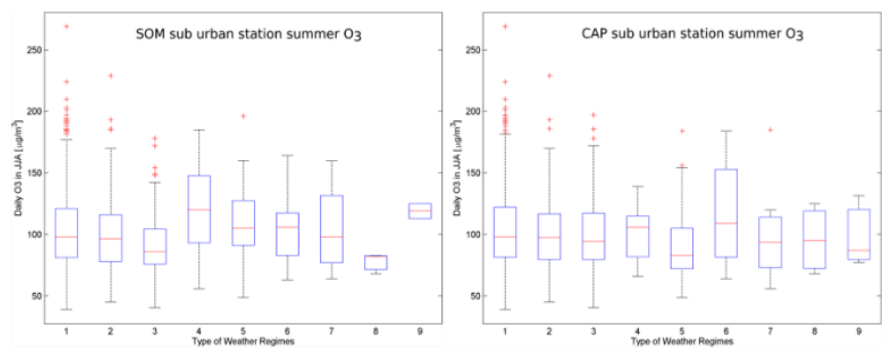

Fig. 5 Daily ozone concentrations and weather regime type in the summer season for SOM and CAP methods

Figs. 6 and 7 show similar weather regime maps at the annual and summer scales that produced by SOM and CAP methods. The maps show that Berlin is in the transition region between two anti-cyclonic systems (over the Atlantic Ocean and Russia). Thus, generally fair weather, low cloud cover and calm winds can be expected in this synoptic configuration. These factors may enhance photochemical ozone production and accumulation from day to day (because of slow removal by transport).
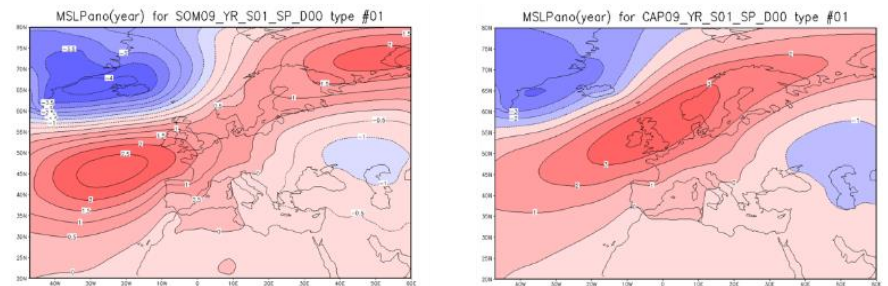

Fig. 6 Annual weather regime type 1 for both SOM and CAP methods
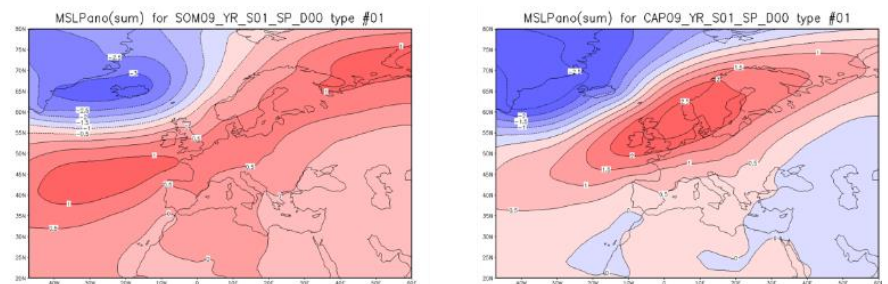

Fig. 7 Summer weather regime type 1 for SOM and CAP methods

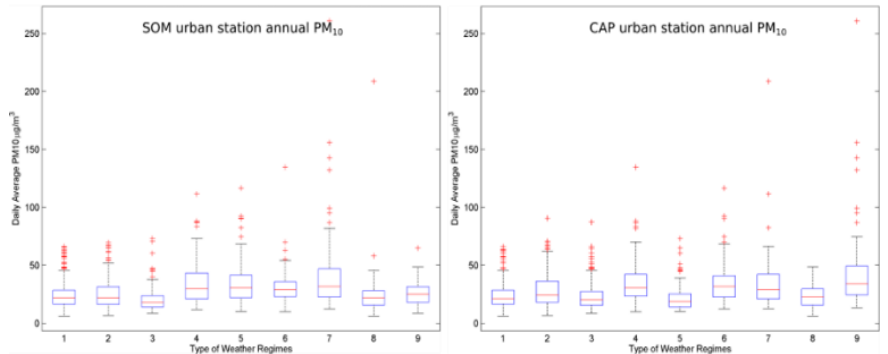

Fig. $8 \mathrm{PM}_{10}$ concentrations in the urban station at the annual scale for both SOM and CAP methods

\subsection{Aerosol Smog PM10}

Aerosol smog $\left(\mathrm{PM}_{10}\right)$ comprises the mass of all particles contained in total suspended particulates with an aerodynamic diameter of less than 10 https://doi.org/10.30799/jespr.210.21070101 $\mu \mathrm{m}$. It is caused by human activity as a result of industrial processes, or it can be of natural origin such as dust. Health studies have shown a measurable reduction in life expectancy with increasing particulate matter concentrations. The box plots Fig. 8 show the highest concentrations in the urban station at the annual scales for both SOM and CAP methods.

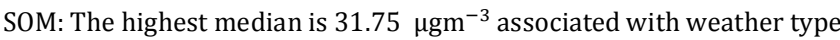
7. The highest max value is $260.71{\mu \mathrm{gm}^{-3}}$ associated with weather type 7 . CAP: The highest median is $34.17 \mathrm{\mu gm}^{-3}$ associated with weather type 9 . Highest max value is $260.71{\mu \mathrm{gm}^{-3}}$ associated with weather type 9 .

From the Fig. 9, the following observations were obtained. SOM: The highest median is $37.48 \mu^{-3}$ associated with weather type 4 . The highest max value is $260.71 \mu^{-3}$ associated with weather type 7. CAP: The highest median is $33.38 \mu^{-3}$ associated with weather type 9 .

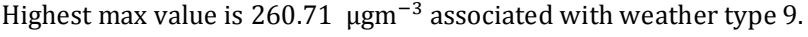

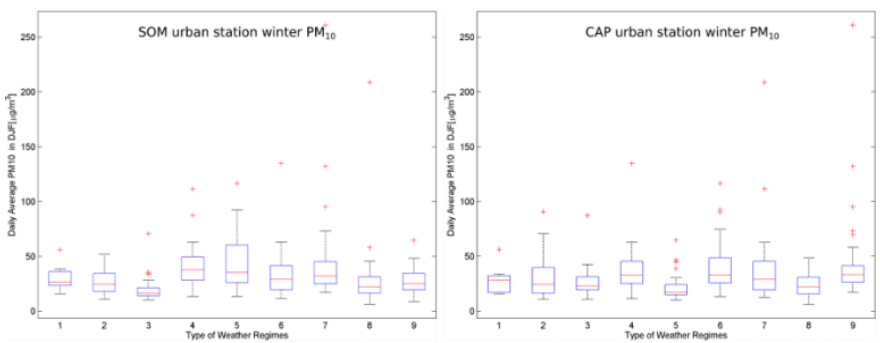

Fig. $9 \mathrm{PM}_{10}$ concentrations in the urban station in winter for both SOM and CAP methods

The weather regime MSLP maps (Figs. 10 and 11) in the urban station at the annual and winter scales are similar for both maps produced by SOM and CAP methods.
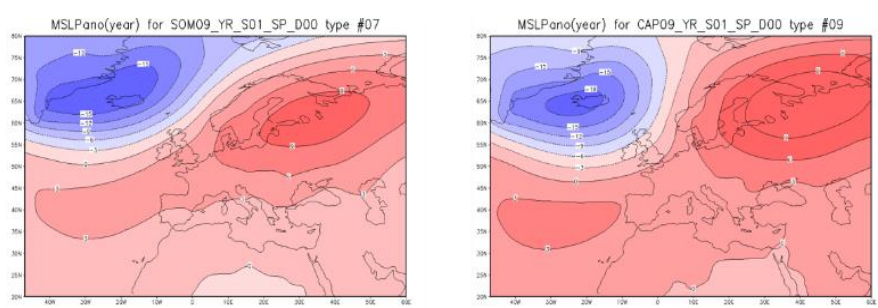

Fig. 10 Weather regime maps at the annual scale for both maps produced by SOM and CAP methods
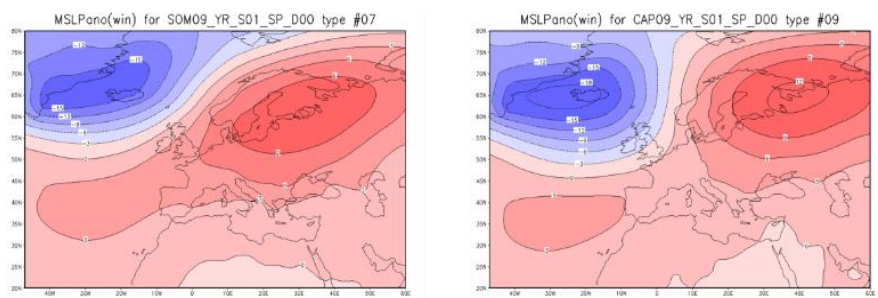

Fig. 11 Winter weather regime maps are Similar to the annual maps.

Results obtained show that Berlin is under the Russian high-pressure system, which extends Central and Northern Europe. This factor enhances the possibility of $\mathrm{PM}_{10}$ accumulation.

\subsection{Nitrogen Dioxide Smog $\mathrm{NO}_{2}$}

The main sources of nitrogen oxides $\left(\mathrm{NO}_{2}\right)$ smog are combustion processes in the industrial and energy production sectors and road transport. It is responsible for summertime ozone production in conjunction with hydrocarbons. In wintertime, ammonium nitrate particles are formed from nitrogen oxides and contribute to the pollution by particulate matter. It is a health risk as a result of high concentrations affect the respiratory function.
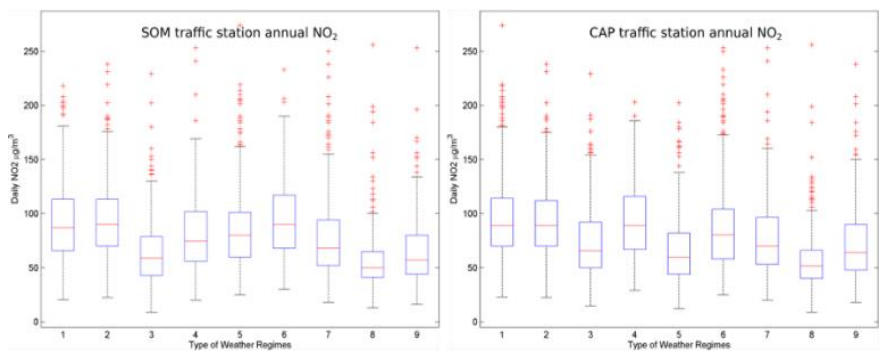

Fig. 12 The annual scale for both SOM and CAP. 
The box plots in Fig. 12 show the highest concentrations and weather regime MSLP maps in the traffic station at the annual scale for SOM and CAP methods. SOM: The highest median is $90 \mu \mathrm{gm}^{-3}$ associated with weather type 2 . The highest max value is $274 \mu^{-3} m^{-3}$ associated with weather type 5. CAP: The highest median is $89 \mu \mathrm{gm}^{-3}$ associated with weather type 1 . The highest max value is $274 \mu^{-3} m^{-3}$ associated with weather type 1.

The box plots of Fig. 13 show the highest concentrations and weather regime MSLP maps in the traffic station at the spring scale for SOM and CAP methods. SOM: The highest median is $102 \mu \mathrm{gm}^{-3}$ associated with weather type 1 . The highest max value is $274 \mu \mathrm{gm}^{-3}$ associated with

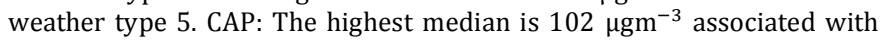
weather type 4 . The highest max value is $274 \mu^{-3 m^{-3}}$ associated with weather type 1 . The traffic station is probably not a very good indicator of the sensitivity of air quality in meteorology, because it is too much affected by local sources.
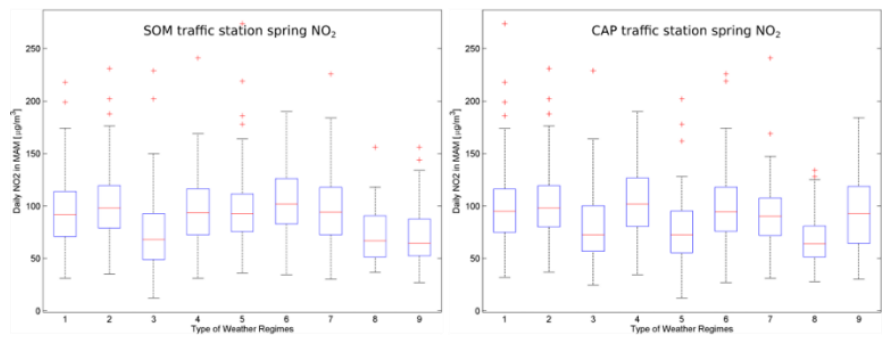

Fig. 13 Spring for both SOM and CAP

The results for the urban station show similar highest concentration and weather regime types during winter for both cluster methods. The similar weather regime maps for both two methods show that Berlin is under a weak pressure that extends from the Atlantic Ocean to Russia. This factor enhances the possibility of $\mathrm{NO}_{2}$ accumulation.

\section{Conclusion}

The study showed similarity results when comparing the boxplots and weather regime maps by SOM09 method and CAP09 cluster method. It observed that the concentration of the air pollutants over Berlin city for the urban, suburban and traffic stations as follows: In the case of ozone $\left(\mathrm{O}_{3}\right)$, the highest concentrations were observed during summer, connected preferentially to weather regime 1 . Same for all methods and station types (urban, suburban and traffic). Also, in the case of $\mathrm{PM}_{10}$, highest concentrations have been observed during winter and autumn connected preferentially to weather regime 7 (SOM), and 9 (CAP) for all stations and highest concentrations observed during spring connected preferentially to weather regime 4 in urban and traffic stations. In addition to that, in the case of $\mathrm{NO}_{2}$, for traffic station, highest concentrations found during spring, connected preferentially to weather regimes 5 and 1 (SOM and CAP), autumn associated with weather type 8 and winter associated with weather types 4 and 6 (SOM and CAP). For urban stations, the highest concentrations were identified during winter are connected preferentially to weather regimes 7 and 9 (SOM and CAP).

\section{Acknowledgment}

This work was supported by the Italian Space Agency (ASI) in the frame of QUITSAT and PRIMES projects, and by the International Center for Theoretical Physics (ICTP) through the Training and Research in Italian Laboratories (TRIL) and Associate Scheme visiting programs. Many thanks to the ministry of higher education and scientific research of Sudan, university of Blue Nile (Sudan), university of Khartoum (Sudan), university of L'Aquila (Italy), university of Bergen (Norway), university of Innsbruck (Austria) and Chinese academy of science in Beijing (China) for funding and hosting my research visits.

\section{References}

[1] I. Muntasir, C. Gabriele, H. Farouk, Air quality assessment over Sudan using NASA remote sensing satellites data and MERRA-2 Model, J. Environ. Sci. Pollut. Res. 6(3) (2020) 438-441.

[2] K. Cheng, W.W. Hao, P. Yi, Y. Zhang, J.Y. Zhang, Volatile organic compounds emission from Chinese wood furniture coating industry: Activity-based emission factor, speciation profiles, and provincial emission inventory, Aerosol Air Qual. Res. 18(11) (2018) 2813-2825.

[3] J. Zhong, X. Zhang, W. Yaqiang, Relative contributions of boundary-layer meteorological factors to the explosive growth of $\mathrm{PM}_{2.5}$ during the red-alert heavy pollution episodes in Beijing in December 2016, J. Meteorol. Res. 31(5) (2017) 809-819.

[4] M. Michael, A. Yadav, S. N. Tripathi, Simulation of trace gases and aerosols over the Indian domain: evaluation of the WRF-Chem model, Geosci. Model Dev. Discuss. 7(1) (2014) 431-482.

[5] R.J. Park, D.J. Jacob, B.D. Field, R.M. Yantosca, M. Chin, Natural and transboundary pollution influences on sulfate-nitrate-ammonium aerosols in the United States: Implications for policy, J. Geophys. Res. D Atmos. 109 (2004) D15204:1-20.

[6] E.M. Leibensperger, L.J. Mickley, D.J. Jacob, Sensitivity of US air quality to midlatitude cyclone frequency and implications of 1980-2006 climate change, Atmos. Chem. Phys. 8(23) (2008) 7075-7086

[7] M. Demuzere, R.M. Trigo, J.V.G. De Arellano, N.P.M. Van Lipzig, The impact of weather and atmospheric circulation on $\mathrm{O}_{3}$ and $\mathrm{PM}_{10}$ levels at a rural midlatitude site, Atmos. Chem. Phys. 9(8) (2009) 2695-2714.

[8] S. Buchholz, J. Junk, A. Krein, G. Heinemann, L. Hoffmann, Air pollution characteristics associated with mesoscale atmospheric patterns in northwest continental Europe, Atmos. Environ. 44(39) (2010) 5183-5190.

[9] A. Russo, R.M. Trigo, H. Martins, M.T. Mendes, $\mathrm{NO}_{2}, \mathrm{PM}_{10}$ and $\mathrm{O}_{3}$ urban concentrations and its association with circulation weather types in Portugal, Atmos. Environ. 89(2) (2014) 768-785.

[10] I. Polo, A. Ullmann, P. Roucou, B. Fontaine, Weather regimes in the EuroAtlantic and Mediterranean sector, and relationship with West African rainfall over the 1989-2008 period from a self-organizing maps approach, J. Clim.

[11] T. Christoudias, A. Pozzer, J. Lelieveld, Influence of the North Atlantic Oscillation on air pollution transport," Atmos. Chem. Phys. 12(2) (2012) 869877.

[12] D.L. Hartmann, J.M. Wallace, V. Limpasuvan, D.W. Thompson, J.R. Holton, The North Atlantic Oscillation: Past, present, and future, Proc. Natl. Acad. Sci. U.S.A. 97(4) (2000) 1412-1417.

[13] J.E. Overland, J. Alheit, A. Bakun, J.W. Hurrell, D.L. Mackas, A.J. Miller, Climate controls on marine ecosystems and fish populations, J. Mar. Syst. 79(3-4)

[14] J. Coria, J. Bonilla, M. Grundström, H. Pleijel, Air pollution dynamics and the need for temporally differentiated road pricing, Transp. Res. Part A Policy Pract. 75 (2015) 178-195.

[15] S. Eckhardt, A. Stohi, S. Beirle, The North Atlantic Oscillation controls air pollution transport to the Arctic, Atmos. Chem. Phys. 3(5) (2003) 1769-1778.

[16] A.G. Triantafyllou, Patterns and concentrations of $\mathrm{PM}_{10}$ in a mountainous basin region, J. Air Waste Manag. Assoc. 50(6) (2000) 1017-1022.

[17] N.T. Lisa, V. Alexander, Xuebin Zhang, Hayley J. Fowler, Claudia Tebaldi, Amanda Lynch, et al., Climate extremes: progress and future directions, Int. J. Climatol. 29(3) (2009) 317-319.

[18] R. Huth, C. Beck, A. Philipp, M. Demuzere, Classifications of atmospheric circulation patterns: Recent advances and applications, Ann. N.Y. Acad. Sci. 1146 (2008) 105-152.

[19] J.P. Zhang, T. Zhu, Q. H. Zhang, C. C. Li, The impact of circulation patterns on regional transport pathways and air quality over Beijing and its surroundings, Atmos. Chem. Phys. 12(11) (2012) 5031-5053.

[20] W.C. Wang, K.S. Chen, Modeling and analysis of source contribution of $\mathrm{PM}_{10}$ during severe pollution events in Southern Taiwan, Aerosol Air Qual. Res. 8(3) (2008) 319-338.

[21] M.R. Leśniok, Z.A. Caputa, The role of atmospheric circulation in air pollution distribution in Katowice Region (Southern Poland), Int. J. Environ. Waste Manag. 4(1-2) (2009) 62-74.

[22] A. Carvalho, A. Monteiro, I. Ribeiro, O. Tchepel, High ozone levels in the northeast of Portugal: Analysis and characterization, Atmos. Environ. 44(8) (2010) 1020-1031.

[23] R.J. Pope, N.H. Savage, M.P. Chipperfield, S.R. Arnold, T.J. Osborn, The influence of synoptic weather regimes on UK air quality: Analysis of satellite column $\mathrm{NO}_{2}$, Atmos. Sci. Lett. 15(3) (2014) 211-217.

[24] R.M. Trigo, P.M. Sousa, Modelling wildfire activity in Iberia with different atmospheric circulation weather types, Int. J. Climatol. 36(7) (2013) 27612778

[25] M.T. Latif, S. Z. Azmi, Z. Johny, The impact of urban growth on regional air quality surrounding the Langat River Basin, Malaysia, Environmentalist 31(3) (2011) 315-324.

[26] N.M. Tahir, S. Suratman, F.T. Fong, M.S. Hamzah, M.T. Latif, Temporal distribution and chemical characterization of atmospheric particulate matter in the eastern coast of Peninsular Malaysia, Aerosol Air Qual. Res. 13(2) (2013) 584-595.

[27] N. Banan, M.T. Latif, L. Juneng, F. Ahamad, Characteristics of surface ozone concentrations at stations with different backgrounds in the Malaysian Peninsula, Aerosol Air Qual. Res. 13(3) (2013) 1090-1106.

[28] N. Bärtsch-Ritter, J. Keller, J. Dommen, A.S.H. Prévôt, Effects of various meteorological conditions and spatial emission resolutions on the ozone concentration \& ROG/NO $/ \mathrm{NO}_{\mathrm{x}}$ limitation in the Milan area (I), Atmos. Chem. Phys. Discuss. 3(1) (2003) 733-768.

[29] C.M. Buchanan, I.J. Beverland, M.R. Heal, The influence of weather-type and long-range transport on airborne particle concentrations in Edinburgh, UK, Atmos. Environ. 36(34) (2002) 5343-5354.

[30] R.G. Derwent, D.S. Stevenson, W.J. Collins, C.E. Johnson, Intercontinental transport and the origins of the ozone observed at surface sites in Europe Atmos. Environ. 38(13) (2004) 1891-1901.

[31] S. Solberg, Y. Orsolini, K. Uhse, European surface ozone in the extreme summer 2003, J. Geophys. Res. Atmos. 113(7) (2008) 9003-9038.

[32] J. Zhong, X. Zhang, Y. Wang, Reflections on the threshold for $\mathrm{PM}_{2.5}$ explosive growth in the cumulative stage of winter heavy aerosol pollution episodes (HPEs) in Beijing, Tellus, Ser. B Chem. Phys. Meteorol. 71(1) (2019) 1-7. 24(13) (2011) 3423-3432. (2010) 305-315.

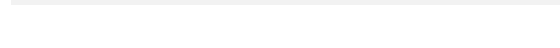


[33] N. Barros, C. Borrego, I. Toll, C. Soriano, P. Jiménez, J.M. Baldasano, Urban photochemical pollution in the iberian peninsula: Lisbon and barcelona airsheds, J. Air Waste Manag. Assoc. 53(3) (2003) 347-359.

[34] A.C. Carvalho, I. Gelpi, M. Barreiro, Influence of topography and land use on pollutants dispersion in the Atlantic coast of Iberian Peninsula, Atmos. Environ. 40 (21) (2006) 3969-3982.

[35] A. Philipp, C. Beck, R. Huth, J. Jacobeit, Development and comparison of circulation type classifications using the COST 733 dataset and software, Int. J. Climatol. 36(7) (2016) 2673-2691.
[36] A. Philipp, J. Bartholy, C. Beck, M. Erpicum, Cost733cat - A database of weather and circulation type classifications, Phys. Chem. Earth 35(9-12) (2010) 360373.

[37] J. Stryhal, R. Huth, Classifications of winter Euro-Atlantic circulation patterns: An intercomparison of five atmospheric reanalyses, J. Clim. 30(19) (2017) 7847-7861.

[38] H. Ritter, T. Kohonen, Self-organizing semantic maps, Biol. Cybern. 61(4) (1989) 241-254. 